\title{
Prevalence of lower limb pain and its associated factors among healthcare workers
}

\author{
H. Mohd Yusoff ${ }^{1}$, R.A. Zawawi ${ }^{1}$ and B.M. Deros ${ }^{2}$ \\ ${ }^{1}$ Faculty of Medicine, Universiti Kebangsaan Malaysia Medical Centre, \\ Bandar Tun Razak, 56000 Cheras, Kuala Lumpur \\ Email: drhanie@ppukm.ukm.edu.my \\ Phone: +603-91455904 Fax: +603-91452277 \\ ${ }^{2}$ Faculty of Engineering \& Built Environment, \\ Universiti Kebangsaan Malaysia \\ 43600 UKM Bangi, Selangor, Malaysia
}

\begin{abstract}
Healthcare workers (HCW) are known to have high prevalence of musculoskeletal problems. Nevertheless, the knowledge on lower limb pain (LLP) and its risk factors is still lacking due to the lack of studies done on this body region. A cross-sectional study was therefore carried out among $\mathrm{HCW}$ in a district hospital in order to identify the prevalence of LLP among HCW and its associated risk factors. LLP was assessed through Malay-translated Standardised Nordic Questionnaire and other personal and work risk factors were elicited. It was found that the majority of the HCW were exposed to prolonged walking $(73.6 \%)$ while $33.8 \%$ experienced their jobs as passive and another $19 \%$ found theirs as highly strained. The prevalence of LLP that lasted more than a day in the previous 12 months was 64.3\%, while the prevalence for chronic duration (more than three months) was $18.0 \%$. Chronic LLP among this population was associated with obesity, history of previous injury and work category. Other physical and psychosocial work factors were not found to be associated with chronic LLP. It could be concluded that LLP is prevalent among HCW. However, prospective cohort study is recommended to ascertain the associations of the work factors and chronic LLP.
\end{abstract}

Keywords: lower limb pain; healthcare workers; prevalence; musculoskeletal disorders

\section{INTRODUCTION}

Musculoskeletal disorder (MSD) has been recognised as the commonest health problem among workers [1]. It is a major concern because it is associated with high adverse impact to both workers and their organisations [2-4]. Healthcare workers (HCW) were found to be among the groups with high prevalence of MSD [5, 6]. In a systematic review of MSD among nurses, it was found that the mean prevalence of MSD among them reached more than 70\% [7]. Even though most studies done among HCW focused on nurses, other providers in the healthcare service were found to have equally high prevalence of MSDs [8]. With regards to the affected anatomical sites, both upper limbs and axial region (neck and low back) were found to be the most commonly affected sites for MSD among HCW $[7,9]$. However, there were studies that showed lower limb musculoskeletal pain was also prevalent among HCW. Tinubu et al [10] found that the knee was the third commonly affected sites with the prevalence of $22.4 \%$ after the neck $(28.0 \%)$ and the lower back $(44.1 \%)$. Also, Amin et al [11] found that the feet had the second highest prevalence of 
MS symptoms (47.2\%) after the neck (49.0\%). Review of literatures revealed that there is a lack of studies on MSD symptoms involving lower limbs [12] and if they were included, only the knee region was studied. Since the lower limbs musculoskeletal pain was not commonly studied, its risk factors among HCW were not well established [13]. However, the risk factors for lower limb pain that has been found in the other group of workers as well as the general population were associated with tasks that are generally common in the daily work of HCW. These include prolonged or long distance walking, prolonged standing, stair climbing, kneeling, squatting and lifting or carrying heavy loads [14-22].

Compared to the physical factors, the psychosocial work factors associated with lower limb pain were even less studied [23]. Nevertheless, among the few studies done, it had been shown that psychosocial factor in the workplace had its role in the development of lower limb pain. Jones et al [24] studied the onset of a new case of knee pain among newly employed workers from 12 diverse occupational settings in a two year prospective study. They found that job monotonous/repetitiveness and job control were significantly associated to the onset of lower limb pain among workers. They also found that general psychological distress predicted the onset of lower limb pain. Another prospective study had been done by Andersen et al [19] to investigate the development of more severe musculoskeletal pain among workers from various industries. Workers were followed-up after 24 months for the increase in the severity of pain. They found that job control together with low job satisfaction and low social supports were significantly associated with the lower limb pain. Therefore, it could be seen that there is a lack of studies focusing on the lower limb pain among HCW and the lack of knowledge on the factors associated with this pain, despite some indications of its burden among HCW from the previous studies. Thus, this study was done to identify the prevalence of lower limb pain and the factors associated with it among HCW.

\section{METHODS AND MATERIALS}

\section{Study Background and Study Sample}

A cross-sectional study was conducted in one of the district hospitals in Pahang, Malaysia. This 498-bed hospital provides secondary healthcare services with multispecialty to a population of nearly 150,000 . There were altogether 2,038 workers in this hospital inclusive of administrative staff. The healthcare workers were mainly doctors, nurses, medical assistants and attendants. From the total of 1,675 healthcare workers in these categories, a stratified random sample was selected based on the different classifications. Only those who worked more than a year in the current hospital were included in this study, while pregnancy, congenital malformation of lower limbs, usage of prosthesis at the lower limbs and refusal to participate were taken as the exclusion criteria. 340 respondents were selected with $92 \%$ who responded to the questionnaires.

\section{Study Instruments}

The self-administered questionnaires were made up of six sections. Socio-demographic section contained respondents' personal characteristics which were age, gender, and marital status. The co-morbidities section was designed to elicit the confounding factors to lower limb musculoskeletal pain which were smoking, history of lower limb injury, body mass index $\left(\mathrm{kg} / \mathrm{m}^{2}\right)$ which were calculated from the self-reported weight (in kilogram) and height (in meter) and other diseases. The body mass index was categorised into normal, overweight and obese according to World Health Organisation (WHO) 
Classification. In this section, Personal Stress Inventory by O'Donnell et al [25] was used to measure the personal stress level of respondents. This inventory consisted of 52 items representing stress symptoms which were rated by a 4 point Likert scale from 'never' (0) to 'nearly every day' (3). The score of 40 and above was taken as the cut-off point for personal stress. This inventory has been translated into Malay, validated, and used in the studies of stress among workers in Malaysia [26, 27]. It was found to have high internal consistency with Cronbach $\alpha$ of 0.88 [28].

The work factors were assessed in three sections which were work characteristics, physical work factors, and psychosocial work factors. Work characteristics elicited the category of work, work unit work schedule, and years of employment. Physical work factors were assessed by five physical activities of the lower limbs which were walking, standing, kneeling, squatting, and handling loads more than 25 kilograms. Each activity was scaled in a 4 point of Likert scale (never or nearly never, less than 2 hours/day, between 2 to 4 hours/day and more than 4 hours/day). For the measurement of psychosocial work factors, Job Content Questionnaire (JCQ) which has been translated and validated [29] was used. The cut-off point for high decision latitude and high psychological job demands were taken as their median scores of the total respondents. The interactions between the decision latitude score and the psychological job demands score would indicate the psychosocial work experience of the respondents. High strain job was defined as having low decision latitude and high psychological job demands. Low strain job was defined as having high decision latitude and low psychological job demands. Active job was defined as having high decision latitude and high psychological job demands. Passive job was defined as having low decision latitude and low psychological job demands.

The fifth section of the questionnaire measured the outcome of the study which was the lower limb pain. This section consisted of the Standardised Nordic Questionnaire (SNQ-M) developed by Kuorinka et al [30] which has been translated into Malay. This questionnaire had an anatomical diagram of body regions. Respondents were asked to mark precisely the area of pain which was defined as pain or discomfort felt for at least one day in the previous 12 months on the lower limb regions (hip/thigh, knee/leg and ankle/foot). In addition, they were asked about the duration of the pain (less than 1 month, between 1 to 3 months and more than 3 months).

\section{Statistical Analysis and Research Ethics}

Statistical analysis of data was done using the IBM SPSS Statistics version 22.0. Chisquare test was used to assess the association between the independent factors and the outcome measures. This study has been approved by the Ethical Committee of Universiti Kebangsaan Malaysia (FF-2015-177) and Malaysian Ministry of Health (NMRR-15-45425208 (IIR).

\section{RESULTS AND DISCUSSION}

\section{Socio-demographic Characteristics, Co-Morbidities and Work Descriptions of the Respondents}

The socio-demography, co-morbidities, and work descriptions of the respondents are presented in Table 1. Majority of the respondents were female $(70.7 \%)$ and married $(69.1 \%)$. Also, the majority of them were young whereby only $17.4 \%$ of them were older than 40 years old. The percentages of respondents who had suffered from the comorbidities varied from $9.6 \%$ to $25.1 \%$. The highest prevalence of co-morbidity was personal stress followed by obesity, having other diseases, smoking, and history of lower 
limb injury. For the work characteristics, majority of the respondents were nurses (53.45) and work in shift $(73.0 \%)$. As for the work unit, majority $(36.7 \%)$ of them worked in the surgical unit, followed by medical unit, emergency unit and intensive care unit. Nearly half $(48.6 \%)$ of the respondents had been employed for 5 years or less.

Analysis of the physical work factors showed that majority of the respondents (73.6\%) walked 4 hours or more during their daily work while about $30 \%$ stood for 4 hours or more while working. It showed that the majority of the healthcare workers were upright during working but they were always moving about. It was also found that $28.0 \%$ of them lifted loads more than 25 kilogram for 2 hours or more during their daily work. For the work task of kneeling and squatting, only about $7 \%$ of them were involved with these postures for 2 hours or more. For the psychosocial work factors, it was found that less than $20.0 \%$ of the respondents felt that their job was a high strain job while another $33.8 \%$ felt that theirs was a passive job.

Table 1. Descriptive analysis of the respondents.

\begin{tabular}{|c|c|c|c|}
\hline Factors & $\mathrm{n}(\%)$ & Factors & $\mathrm{n}(\%)$ \\
\hline \multicolumn{2}{|c|}{ Socio-demographic characteristics } & Physical work factors & \\
\hline Female & $220(70.7)$ & Walking $\geq 4$ hours/day & $229(73.6)$ \\
\hline Age $>40$ years old & $54(17.4)$ & Standing at a place $\geq 4$ hours/day & $94(30.2)$ \\
\hline \multirow[t]{2}{*}{ Married } & $215(69.1)$ & Kneeling $\geq 2$ hours/day & $22(7.1)$ \\
\hline & & Squatting $\geq 2$ hours/day & $22(7.1)$ \\
\hline Co-morbidities & & Lifting loads $>25 \mathrm{~kg} \geq 2$ hours/day & $87(28.0)$ \\
\hline Smoking & $31(10.0)$ & & \\
\hline Obese $(\mathrm{BMI} \geq 30)$ & $46(14.8)$ & & \\
\hline Having other diseases & $39(12.5)$ & Psychosocial work factors & \\
\hline $\begin{array}{l}\text { History of lower limb } \\
\text { injury }\end{array}$ & $30(9.6)$ & High strain job & $59(19.0 \%)$ \\
\hline Personal stress & $78(25.1)$ & Passive job & $105(33.8 \%)$ \\
\hline \multicolumn{4}{|l|}{ Work characteristics } \\
\hline Work categories & & Work schedule & \\
\hline Doctors & $72(23.2)$ & Shift work & $226(73.0)$ \\
\hline Medical assistants & $24(7.7)$ & Office hours & $84(27.0)$ \\
\hline Nurses & $166(53.4)$ & & \\
\hline Attendants & $49(15.7)$ & & \\
\hline Work unit & & Years of employment & \\
\hline Emergency & $65(20.9)$ & $\leq 5$ & $151(48.6)$ \\
\hline Surgery & $114(36.7)$ & $6-10$ & $67(21.5)$ \\
\hline Medical & $97(31.2)$ & $11-15$ & $46(14.8)$ \\
\hline Intensive care unit (ICU) & $35(11.2)$ & $>15$ & $47(15.1)$ \\
\hline
\end{tabular}

\section{Prevalence of Lower Limb Pain}

The prevalence of lower limb pain among respondents is demonstrated in Table 2. About $64 \%$ of the total respondents had experienced lower limb pain that lasted more than a day in the previous 12 months. Among them, nearly $50 \%$ had one site pain which translated into $29.9 \%$ of the total respondents. Involvement of the three sites was not uncommon 
where 33 respondents had experienced the pain. This made up to $10.6 \%$ of the total respondents. The prevalence of one site lower limb pain in this study was similar to the median of annual lower limb pain prevalence from the studies done among HCW [12]. This may be so since the majority of these studies focused on the prevalence of pain for each site of the body such as the knee.

When the chronicity of the lower limb pain was considered, it was found that $18 \%$ of the respondents experienced chronic pain and the majority of them (67.9\%) had one site pain. Chronic pain at all the three sites of lower limb was small whereby only $7.1 \%$ of them was involved. This translated into $1.3 \%$ of the total respondents. Even though the prevalence of chronic lower limb pain was much lower than the prevalence of the total lower limb pain experienced (18.0\% and $64.3 \%$, respectively), it should still be a major concern. This is because chronic pain at lower limb had the potential to progress to other body regions. It had been found that chronic knee pain increased the risk of developing chronic pain in other body regions up to three times more than those without lower limb pain while the risk was not significantly increased for the sub chronic pain [31]. Also, chronic pain in one site of the lower limb had been found to disturb the dynamic functions of the whole limb [32]. Walking, for example, involves accurate dynamics of the structures involved $[33,34]$. Since the work of the majority of HCW had been shown to involve a lot of walking, the possibility of the chronic lower limb pain jeopardising their mobility and thus their work productivity is high. Therefore, further study to find the impact of the chronic lower limb pain on the work productivity of HCW is warranted.

Table 2. The prevalence of lower limb pain.

\begin{tabular}{|c|c|c|c|}
\hline \multicolumn{4}{|c|}{ 12-month prevalence of lower limb pain } \\
\hline Pain characteristic & $\mathrm{n}(\%)$ & Pain characteristic & $\mathrm{n}(\%)$ \\
\hline Pain at least for 1 day & $200(64.3)$ & Chronic pain (> 3months) & $56(18.0)$ \\
\hline By sites & & By sites & \\
\hline 1 site of lower limb & $93(46.5)$ & 1 site of lower limb & 38 (67.9) \\
\hline 2 sites of lower limb & $74(37.0)$ & 2 sites of lower limb & $14(25.0)$ \\
\hline 3 sites of lower limb & $33(16.5)$ & 3 sites of lower limb & $4(7.1)$ \\
\hline
\end{tabular}

\section{Socio-demographic and Co-morbidity Factors and Chronic Lower Limb Pain}

There was no significant association found between socio-demographic factors and chronic lower limb pain (Table 3). However, two co-morbidity factors were found to be significantly associated with chronic lower limb pain. They were poor BMI and history of lower limb injury. The prevalence of chronic lower limb pain among those who were obese was significantly higher $(32.6 \%)$ than those who were overweight $(14.5 \%)$ or having a normal BMI (15.9\%). Obesity has been recognised as a condition that increases the risk of osteoarthritis of the weight-bearing body structures [35-37]. Mechanically, any load-carrying structures are bound to be subjected to loading stress and fatigue [38]. Even though obesity is a personal risk factor, it can be intervened at the workplace level. World Health Organisation has recognised workplace as a good platform to control chronic lifestyle diseases where weight reduction programmes may be initiated to these obese workers.

Those who had a previous history of lower limb injury were also presented with a significantly higher prevalence (33.3\%) of chronic lower limb pain as compared to those who had none $(16.4 \%)$. Majority of the previous studies on osteoarthritis of the lower 
limb had similar findings [39]. It was found that previous injury to the knee increased the risk of knee osteoarthritis by nearly four times.

Table 3. The associations between socio-demographic and co-morbidity factors and chronic lower limb pain.

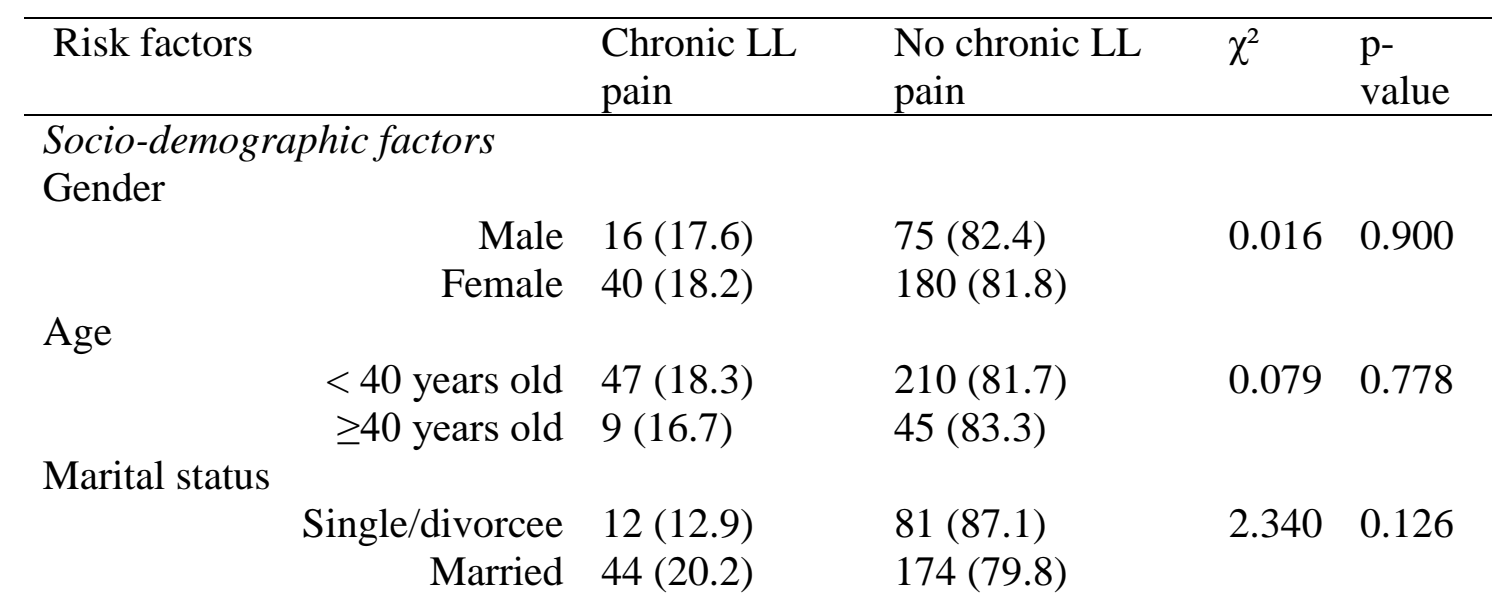

\section{Co-morbidities}

Smoking

$\begin{array}{lllll}\text { Yes } & 6(19.4) & 25(80.6) & 0.042 & 0.837 \\ \text { No } & 50917.9) & 230(82.1) & & \end{array}$

BMI

Normal $\left(\mathrm{BMI}<24.9 \mathrm{~kg} / \mathrm{m}^{2}\right) \quad 29(15.9)$

Overweight (BMI: 25-

$12(14.5)$

$\left.29.9 \mathrm{~kg} / \mathrm{m}^{2}\right)$

Obese $\left(\mathrm{BMI} \geq 30 \mathrm{~kg} / \mathrm{m}^{2}\right) \quad 15(32.6)$
$153(84.1)$

$70(85.5)$

$31(67.4)$

$7.8810 .019 *$

Having other diseases

$$
\text { Yes } 7 \text { (17.9) }
$$

$0.000 \quad 0.992$

History of lower limb injury

$\begin{array}{lllll}\text { Yes } & 10(33.3) & 20(66.7) & 5.283 & 0.022^{*} \\ \text { No } & 46(16.4) & 235(83.6) & & \end{array}$

Personal stress

\begin{tabular}{cllll} 
Yes & $17(21.8)$ & $61(78.2)$ & 1.012 & 0.314 \\
No & $39(16.7)$ & $194(83.3)$ & & \\
\hline
\end{tabular}

*Significant at $\mathrm{p}<0.05$

\section{Work Factors and Chronic Lower Limb Pain}

The associations of work factors and chronic lower limb pain are shown in Tables 4 and 5. The only work factor that was found to be significantly associated with chronic lower limb pain was the work category (Table 4). Doctors were found to have the highest prevalence $(26.4 \%)$ while attendants had the smallest prevalence of chronic lower limb 
pain. This finding was not in tandem with the common findings in the studies on MSDs among HCW [40].

Table 4. The associations between work characteristics and chronic lower limb pain.

\begin{tabular}{|c|c|c|c|c|}
\hline Work risk factors & Chronic LL pain & No chronic LL pain & $\chi^{2}$ & p-value \\
\hline \multicolumn{5}{|l|}{ Work category } \\
\hline Doctors & $19(26.4)$ & $53(73.6)$ & 8.143 & $0.043^{*}$ \\
\hline Medical assistants & $4(16.7)$ & $20(83.3)$ & & \\
\hline Nurses & $30(18.1)$ & $136(81.9)$ & & \\
\hline Attendants & $3(6.1)$ & $46(93.9)$ & & \\
\hline \multicolumn{5}{|l|}{ Work unit } \\
\hline Emergency & $10(15.4)$ & $55(84.6)$ & 1.139 & 0.768 \\
\hline Surgery & $22(19.3)$ & $92(80.7)$ & & \\
\hline Medical & $16(16.5)$ & $81(83.5)$ & & \\
\hline Intensive care unit (ICU) & $8(22.9)$ & $27(77.1)$ & & \\
\hline \multicolumn{5}{|l|}{ Work schedule } \\
\hline Shift work & $38(16.8)$ & $188(83.2)$ & 0.796 & 0.372 \\
\hline Office hours & $18(21.2)$ & $67(78.8)$ & & \\
\hline \multicolumn{5}{|l|}{ Years of employment } \\
\hline$\leq 5$ & $29(19.2)$ & $112(80.8)$ & 7.172 & 0.067 \\
\hline $6-10$ & $6(9.0)$ & $61(91.0)$ & & \\
\hline $11-15$ & $13(28.3)$ & $33(71.7)$ & & \\
\hline$>15$ & $8(17.0)$ & $39(83.0)$ & & \\
\hline
\end{tabular}

*Significant at $\mathrm{p}<0.05$

Table 5. The associations between physical and psychosocial work factors and chronic lower limb pain.

\begin{tabular}{|c|c|c|c|c|}
\hline Work risk factors & Chronic LL pain & No chronic LL pain & $\chi^{2}$ & p-value \\
\hline \multirow{2}{*}{\multicolumn{5}{|c|}{$\begin{array}{l}\text { Physical work factors } \\
\text { Walking }\end{array}$}} \\
\hline & & & & \\
\hline$<4$ hours/day & $11(13.4)$ & $71(86.6)$ & 1.590 & 0.207 \\
\hline$\geq 4$ hours/day & $45(19.7)$ & $184(80.3)$ & & \\
\hline \multicolumn{5}{|l|}{ Standing } \\
\hline$<4$ hours/day & $34(15.7)$ & $183(84.3)$ & 2.659 & 0.105 \\
\hline$\geq 4$ hours/day & $22(23.4)$ & $72(76.6)$ & & \\
\hline \multicolumn{5}{|l|}{ Kneeling } \\
\hline$<2$ hours/day & $51(17.6)$ & $238(82.4)$ & 0.357 & 0.550 \\
\hline$\geq 2$ hours/day & $5(22.7)$ & $17(77.3)$ & & \\
\hline \multicolumn{5}{|l|}{ Squatting } \\
\hline$\geq 2$ hours/day & $5(22.7)$ & $\begin{array}{l}258(82.4) \\
17(77.3)\end{array}$ & 0.551 & 0.550 \\
\hline \multicolumn{5}{|l|}{ Lifting loads $>25 \mathrm{~kg}$} \\
\hline$<2$ hours/day & $43(19.2)$ & $181(80.8)$ & 0.768 & 0.381 \\
\hline$\geq 2$ hours/day & $13(14.9)$ & $74(85.1)$ & & \\
\hline \multicolumn{5}{|l|}{ Psychosocial Work Factors } \\
\hline High strain job & $9(15.3)$ & $50(84.7)$ & 2.304 & 0.512 \\
\hline Low strain job & $16(23.5)$ & $52(76.5)$ & & \\
\hline Active job & $15(19.0)$ & $64(81.0)$ & & \\
\hline
\end{tabular}


*Significant at $\mathrm{p}<0.05$

Previous studies showed nurses as having the highest prevalence of pain as compared to other categories of HCW and numerous studies had been done among them as compared to doctors [41-43]. There is a lack of knowledge on MSD among doctors. Among the limited number of lower limb studies that included doctors, it was found that the risk among doctors in Chinese medicine was two times higher than dentists while there was no significant difference between nurses and dentists [8]. Also, Mehrdad et al [44] found that longer work hour per shift had significantly increased the risk of knee pain as compared to low back pain and neck pain. This might be associated with the finding of this study where doctors worked longer hours per day as compared to other categories who worked in shifts with shorter work hours $[45,46]$. As for the other work factors, there was no significant relationship between them and chronic lower limb pain. This may be due to the design of this study where those who had already developed pain might not be doing the high risk work tasks anymore and thus had lower work exposures [47, 48].

\section{CONCLUSIONS}

Lower limb pain is a common phenomenon among HCW. This study showed that lower limb pain which lasted for more than a day in the preceding 12 months affected more than half of the HCW. For chronic lower limb pain which lasted more than 3 months, it affected about one-fifth of them. Obesity, history of lower limb injury, and work category were found to associate with the chronic lower limb pain. However, both the physical and psychosocial work factors were not found to associate with the pain. The exposure to these work factors, nevertheless, could have been modified earlier to a lower level by the workers or employers for those who had developed chronic lower limb pain. Thus, further study with a prospective cohort design is recommended to assess the relationships between these work factors and chronic lower limb pain Also, a study on the impact of the chronic lower limb pain on work productivity should be encouraged as this study showed that the majority of the HCW were exposed to prolonged walking.

\section{ACKNOWLEDGEMENTS}

We, the authors, would like to thank Professor Rusli Nordin from Jeffrey Cheah School of Medicine and Health Sciences, Monash University Malaysia for his permission to use the Malay-translated Job Content Questionnaire (M-JCQ). We would also like to thank the Faculty of Medicine, Universiti Kebangsaan Malaysia and Ministry of Health for the permission to conduct this study and all the respondents who volunteered to participate. This study was self-funded and the authors declare that there is no conflict of interest.

\section{REFERENCES}

[1] Jones J, Huxtable C, Hodgson J. Self-reported work-related illness in 2004/05: results from the Labour Force Survey. Retrieved from http://www.hse.gov.uk/ statistics/swi/swi0405.pdf. 1 November, 2016.

[2] Van den Heuvel SG, IJmker S, Blatter BM, De Korte EM. Loss of productivity due to neck/shoulder symptoms and hand/arm symptoms: Results from the PROMO-Study. Journal of Occupational Rehabilitation. 2007;17:370-82. 
[3] Bültmann U, Franche R-L, Hogg-Johnson S, Côté P, Lee H, Severin C, et al. Health status, work limitations, and return-to-work trajectories in injured workers with musculoskeletal disorders. Quality of Life Research. 2007;16:1167-78.

[4] Boström M, Dellve L, Thomée S, Hagberg M. Risk factors for generally reduced productivity - a prospective cohort study of young adults with neck or upperextremity musculoskeletal symptoms. Scandinavian Journal of Work, Environment \& Health. 2008:120-32.

[5] Ngan K, Drebit S, Siow S, Yu S, Keen D, Alamgir H. Risks and causes of musculoskeletal injuries among health care workers. Occupational Medicine. 2010;60:389-94.

[6] Harcombe H, Herbison G, McBride D, Derrett S. Musculoskeletal disorders among nurses compared with two other occupational groups. Occupational Medicine. 2014;64:601-7.

[7] Ellapen T, Narsigan S. Work related musculoskeletal disorders among nurses: Systematic Review. Journal of Ergonomics 2014.4:S4-003.

[8] Wang SY, Liu LC, Lu MC, Koo M. Comparisons of musculoskeletal disorders among ten different medical professions in Taiwan: a nationwide, populationbased study. PloS ONE. 2015;10:e0123750.

[9] Jellad A, Lajili H, Boudokhane S, Migaou H, Maatallah S, Frih ZBS. Musculoskeletal disorders among Tunisian hospital staff: Prevalence and risk factors. The Egyptian Rheumatologist. 2013;35:59-63.

[10] Tinubu BM, Mbada CE, Oyeyemi AL, Fabunmi AA. Work-related musculoskeletal disorders among nurses in Ibadan, South-west Nigeria: a crosssectional survey. BMC Musculoskeletal disorders. 2010;11:12.

[11] Amin NA, Nordin R, Fatt QK, Noah RM, Oxley J. Relationship between psychosocial risk factors and work-related musculoskeletal disorders among public hospital nurses in Malaysia. Annals of Occupational and Environmental Medicine. 2014;26:23.

[12] Davis KG, Kotowski SE. Prevalence of musculoskeletal disorders for nurses in hospitals, long-term care facilities, and home health care: A comprehensive review. Human Factors 2015.57:754-92.

[13] da Costa BR, Vieira ER. Risk factors for work-related musculoskeletal disorders: A systematic review of recent longitudinal studies. American Journal of Industrial Medicine. 2010;53:285-323.

[14] Palmer KT. Occupational activities and osteoarthritis of the knee. British Medical Bulletin. 2012;102:147-70.

[15] Lau E, Cooper C, Lam D, Chan V, Tsang K, Sham A. Factors associated with osteoarthritis of the hip and knee in Hong Kong Chinese: obesity, joint injury, and occupational activities. American Journal of Epidemiology. 2000;152:855-62.

[16] Pope D, Hunt I, Birrell F, Silman A, MacFarlane GJ. Hip pain onset in relation to cumulative workplace and leisure time mechanical load: a population based casecontrol study. Annals of The Rheumatic Diseases. 2003;62:322-6.

[17] Chee HL, Rampal KG. Work-related musculoskeletal problems among women workers in the semiconductor industry in Peninsular Malaysia 1998. International Journal of Occupational and Environmental Health.10:63-71.

[18] Nahit E, MacFarlane GJ, Pritchard C, Cherry N, Silman A. Short term influence of mechanical factors on regional musculoskeletal pain: a study of new workers from 12 occupational groups. Occupational and environmental medicine. 2001;58:374-81. 
[19] Andersen JH, Haahr JP, Frost P. Risk factors for more severe regional musculoskeletal symptoms: A two-year prospective study of a general working population. Arthritis \& Rheumatology. 2007;56:1355-64.

[20] Cogon D, Kellingray S, Inskip H, Croft P, Campbell L, Cooper C. Osteoarthritis of the hip and occupational lifting. American Journal of Epidemiology. 1998;147:523-8.

[21] Dahaghin S, Tehrani-Banihashemi S, Faezi S, Jamshidi A, Davatchi F. Squatting, sitting on the floor, or cycling: Are life-long daily activities risk factors for clinical knee osteoarthritis? Stage III results of a community-based study. Arthritis and rheumatism 2009.61:1337-42.

[22] Baker P, Reading I, Cooper C, Coggon D. Knee disorders in the general population and their relation to occupation. Occupational and Environmental Medicine 2003.60:794-7.

[23] Macfarlane GJ, Pallewatte N, Paudyal P, Blyth FM, Coggon D, Crombez G, et al. Evaluation of work-related psychosocial factors and regional musculoskeletal pain: results from a EULAR Task Force. Annals of the Rheumatic Diseases 2009.68:885-91.

[24] Jones GT, Harkness EF, Nahit ES, McBeth J, Silman AJ, Macfarlane GJ. Predicting the onset of knee pain: results from a 2-year prospective study of new workers. Annals of the Rheumatic Diseases 2007.66:400-6.

[25] O'Donnell M, Jaffe D, Zindler Wernet P. Stress assessment. In: O’Donnell MP, Ainsworth TH, editors. Health Promotion in the Work Place, John Wiley, New York. 1984:185-220.

[26] Banon A, Ismail N. Stress intervention study among health nursing staff in Terengganu. Journal of Community Health 2009. 2001;15:93.

[27] Mohd ZI, Noor HI. A study of occupational stress and coping strategies among correctional officers in Kedah, Malaysia. Journal of Community Health 2010.16:66.

[28] Yusoff H, Ismail N. Prevalence of stress and its influencing factors among school teachers in Selangor. Journal of Community Health 2009. 2003;15:97.

[29] Edimansyah B, Rusli B, Naing L, Mazalisah S. Reliability and construct validity of the Malay version of the Job Content Questionnaire (JCQ). Southeast Asian Journal of Tropical Medicine and Public Health 2006.37:412-6.

[30] Kuorinka I, Jonsson B, Kilbom A, Vinterberg H, Biering-Sørensen F, Andersson G, et al. Standardised Nordic Questionnaires for the analysis of musculoskeletal symptoms. Applied Ergonomics 1987.18:233-7.

[31] Andersen L, Clausen T, Carneiro I, Holtermann A. Spreading of chronic pain between body regions: prospective cohort study among health care workers. European Journal of Pain 2012.16:1437-43.

[32] Thomas AC, Villwock M, Wojtys EM, Palmieri-Smith RM. Lower extremity muscle strength after anterior cruciate ligament injury and reconstruction. Journal of Athletic Training 2013.48:610-20.

[33] Chin LC, Basah SNB, bin Yaacob S, Ewe Y. Conceptual design and implementation for visual tracking ankle rehabilitation system. Journal of Mechanical Engineering and Sciences 2014.7:1208-18.

[34] Kinugasa T, Ando K, Fujimoto S, Yoshida K, Iribe M. Development of a threedimensional dynamic biped walking via the oscillation of telescopic knee joint and its gait analysis. Journal of Mechanical Engineering and Sciences 2015.9:1529-37. 
[35] Heidari B. Knee osteoarthritis prevalence, risk factors, pathogenesis and features: Part I. Caspian Journal of Internal Medicine 2011.2:205.

[36] Uddin MS, Hossain MM, Islam MS, Haque MO, Kulsum U, Rahman E, et al. Prevalence of obesity among musculoskeletal patients. International Journal of Physiotherapy and research 2015.3:889-93.

[37] Knight JA. Diseases and Disorders Associated with Excess Body Weight. Annals of Clinical \& Laboratory Science 2011.41:107-21.

[38] Mohamed MA, Manurung YH, Ghazali FA, Karim AA. Finite element-based fatigue life prediction of a load-carrying cruciform joint. Journal of Mechanical Engineering and Sciences 2015.8:1414-25.

[39] Blagojevic M, Jinks C, Jeffery A, Jordan K. Risk factors for onset of osteoarthritis of the knee in older adults: a systematic review and meta-analysis. Osteoarthritis and Cartilage 2010.18:24-33.

[40] Wong T, Teo N, Kyaw M. Prevalence and risk factors associated with low back pain among health care providers in a district hospital. Malaysian Orthopaedic Journal 2010.4:23-8.

[41] Karahan A, Kav S, Abbasoglu A, Dogan N. Low back pain: prevalence and associated risk factors among hospital staff. Journal of Advanced Nursing 2009.65:516-24.

[42] Davis K, Kotowski S. Prevalence of musculoskeletal disorders for nurses in hospitals, long-term care facilities, and home care health care: a comprehensive review. Human Factors 2015.57:754-92.

[43] Occhionero V, Korpinen L, Gobba F. Upper limb musculoskeletal disorders in healthcare personnel. Ergonomics 2014.57:1166-91.

[44] Mehrdad R, Morshedizadeh M. Musculoskeletal disorders and ergonomic hazards among Iranian physicians. Archives of Iranian Medicine 2012.15:370-4.

[45] Asch DA, Bilimoria KY, Desai SV. Residents duty hours and medical education policy- raising the evidence bar. The New England Journal of Medicine 2017.376:1704-6.

[46] Nievas IFF, Thaver D. Work-life balance: A different scale for doctors. Frontiers in Pediatrics 2015.3:115.

[47] Osmotherly P, Attia J. The healthy worker survivor effect in a study of neck muscle performance measures in call-centre operators. Work 2006.26:399-406.

[48] Siebert U, Rothenbacher D, Daniel U, Brenner H. Demonstration of the healthy worker survivor effect in a cohort of workers in the construction industry. Occupational \& Environmental Medicine 2001.58:774-9. 